\title{
First record of three species of soil nematodes of the suborder Cephalobina from Ladakh region, Jammu \& Kashmir, India
}

\author{
Anjum N. Rizvi \\ Zoological Survey of India, Northern Regional Centre, 218, Kaulagarh Road, Dehradun, Uttarakhand 248195, India \\ Email: anrizvi@gmail.com
}

\begin{abstract}
The present paper reports three species of soil nematodes of the suborder Cephalobina collected from Ladakh region of the Jammu \& Kashmir State, India. Two species, Cervidellus vexilliger (de Man, 1880) Thorne, 1937 and Chiloplacus demani (Thorne, 1925) Thorne, 1937 are reported for the first time from India, while, Acrobeloides nanus (de Man, 1880) Anderson 1968 is a first record from Ladakh. The species dealt with here have been adequately described and photomicrographed, with additional notes provided on variations encountered in measurements. The occurrence of these species from trans-Himalayan zone conforms with the zoogeographical pattern of distribution of the invertebrate fauna of the zone which harbours both Palaearctic and Oriental elements.
\end{abstract}

Keywords: Acrobeloides nanus, Cervidellus vexilliger, Chiloplacus demani, first record, Ladakh, India, soil nematodes.

Ladakh is home to some very beautiful lakes, which play significant hydrological roles. Three of these lakes surveyed were Pangong Tso, Tsomoriri and Tsokar. These lakes have conservation values, particularly as breeding ground for Bar-headed Goose Anser indicus (Latham, 1790) and globally threatened Black-necked Crane Grus nigricollis Przhevalsky, 1876. Ladakh region of the state

Date of publication (online): 26 October 2010

Date of publication (print): 26 October 2010

ISSN $0974-7907$ (online) | 0974-7893 (print)

Editor: Wasim Ahmad

\section{Manuscript details:}

Ms \# 02259

Received 13 July 2009

Final revised received 01 October 2010

Finally accepted 03 October 2010

Citation: Rizvi, A.N. (2010). First record of three species of soil nematodes of the suborder Cephalobina from Ladakh region, Jammu \& Kashmir, India. Journal of Threatened Taxa 2(11): 1286-1290

Copyright: (c) Anjum N. Rizvi 2010. Creative Commons Attribution 3.0 Unported License. JoTT allows unrestricted use of this article in any medium for non-profit purposes, reproduction and distribution by providing adequate credit to the authors and the source of publication.

Acknowledgements: The author is grateful to the Director, Zoologica Survey of India, Kolkata, for providing necessary facilities and to the Officer-in-Charge, Zoological Survey of India, Northern Regional Station, Dehradun for encouragements.

\section{OPEN ACCESS | FREE DOWNLOAD}

of Jammu \& Kashmir, regarded as the cold desert of India, is least explored in terms of plant and soil nematodes and there are only three species hitherto known from Leh namely, Anguina tritici (Steinbuch, Filipjev) by Zaki \& Mir (1994), Laimydorus vulvapapillatus and Mesodorylaimus ladakhiensis by Mushtaq \& Ahmad (2006).

The studies on soil nematodes collected from the recent survey of Ladakh (July 2008), revealed two new records for India, Cervidellus vexilliger (de Man, 1880) Thorne, 1937 and Chiloplacus demani (Thorne, 1925) Thorne, 1937, while, Acrobeloides nanus (de Man, 1880) Anderson, 1968 is being recorded for the first time from Ladakh.

Material \& Methods: The Cold Deserts in the Ladakh ( $\mathrm{J} \& \mathrm{~K}$ ) was surveyed by the Zoological Survey of India Expedition teams under the programme "Rapid Survey for Assessment of Faunal Resources in Cold Desert of Ladakh" from 01 July 2008 to 30 September 2008. Three lakes surveyed were Pangong Tso, Tsomoriri and Tsokar. Pangong Tso is a long brackish lake spanning Indo Chinese border (only one-third is in India and two-third lies in China). It is situated at $33^{\circ} 50^{\prime} \mathrm{N} \& 78^{\circ} 35^{\prime} \mathrm{E}, 4218 \mathrm{~m}$ and 65000ha area. The water freezes to a depth of several meters in winters. There are some brackish to saline marshes near the western end, whereas surrounding hillside supports low thorn scrub and perennial herbs. Tsomoriri is the largest of the high altitude Trans-Himalayan brackish water lake to lie entirely within Indian Territory. The lake was declared as a Wetland of International Importance under the Ramsar Convention in 2003. The lake now has the distinction of being the highest Ramsar site in the world surpassing Salar de Tara in Chile. The lake is approximately $19 \mathrm{~km}$ long and $7 \mathrm{~km}$ wide and is located at an altitude of $4595 \mathrm{~m}$ and $32^{\circ} 59^{\prime} \mathrm{N} \& 78^{\circ} 20^{\prime} \mathrm{E}$. It is fed by a number of small glacial streams. Vegetation does not appear in the deeper part, but occurs in the shallower part. Various species of sedges and reeds grow in the marshes like Carex, Caragana, typical of the surrounding arid steppe vegetation. The third lake surveyed was the Tsokar. Tsokar is a hyper saline lake of 22000ha. It is situated at an altitude of $4539 \mathrm{~m}$ and at $33^{\circ} 50^{\prime} \mathrm{N}$ \& $78^{\circ} 35^{\prime} \mathrm{E}$. The arid steppe vegetation of surrounding areas is dominated by species of Astragalus and Caragana.

The soil samples, for the extraction of nematodes 
were collected from the root zone (rhizosphere) of the Myricaria, a medicinal shrub and Caragana bushes, which occur very widely around Ladakh wetlands like Pangong Tso, Tsokar and Tsomoriri. The nematodes were isolated from soil by Cobb's sieving and decantation technique, fixed in hot $4 \%$ formalin and dehydrated by slow method. Permanent wax slides were prepared for the study of nematodes. Measurements were made with an ocular micrometer on BX51 DIC Olympus microscope and photomicrographs taken with DP20 digital camera.

Results: The three species extracted have been studied, photomicrographed and described here as under.

\section{Cervidellus vexilliger (de Man, 1880) Thorne, 1937 (Fig. 1)}

1880. Cephalobus vexilliger de Man, Tijds.Nederland. Dierk. Vereen, 5: 1-104.
1937. Cervidellus vexilliger, Thorne, Proc. Helminth. Soc. Wash., 4:1-16

Material Examined: 24.vii.2008, 8 females, 4 males, Pangong Tso, Ladakh, J \& K, India, coll. A.N. Rizvi, NRS/ ZSI/IV/N/401; 26.vii.2008, 7 females, Tsomoriri lake, Ladakh, J \& K, India, coll. A.N. Rizvi, NRS/ZSI/IV/N/402.

Measurements: Refer Table1.

Description: Female: Body generally slightly arcuate ventrally or almost straight upon fixation. Cuticle distinctly annulated. Lateral field with three incisures, of which the middle one diminishes at the anterior end of the phasmid and two outer ones extend beyond phasmid. Lip region with six labial and four cephalic papillae. Primary and secondary axils similar in shape, each with two guarding processes. Lips symmetrical, with three tines each. Labial probolae 3-5 $\mu \mathrm{m}$ long, $\mathrm{Y}$ shaped. Stoma cephaloboid. Pharyngeal corpus cylindrical, isthmus short and basal bulb pyriform to ovoid with valves. Cardia conoid. Rectum
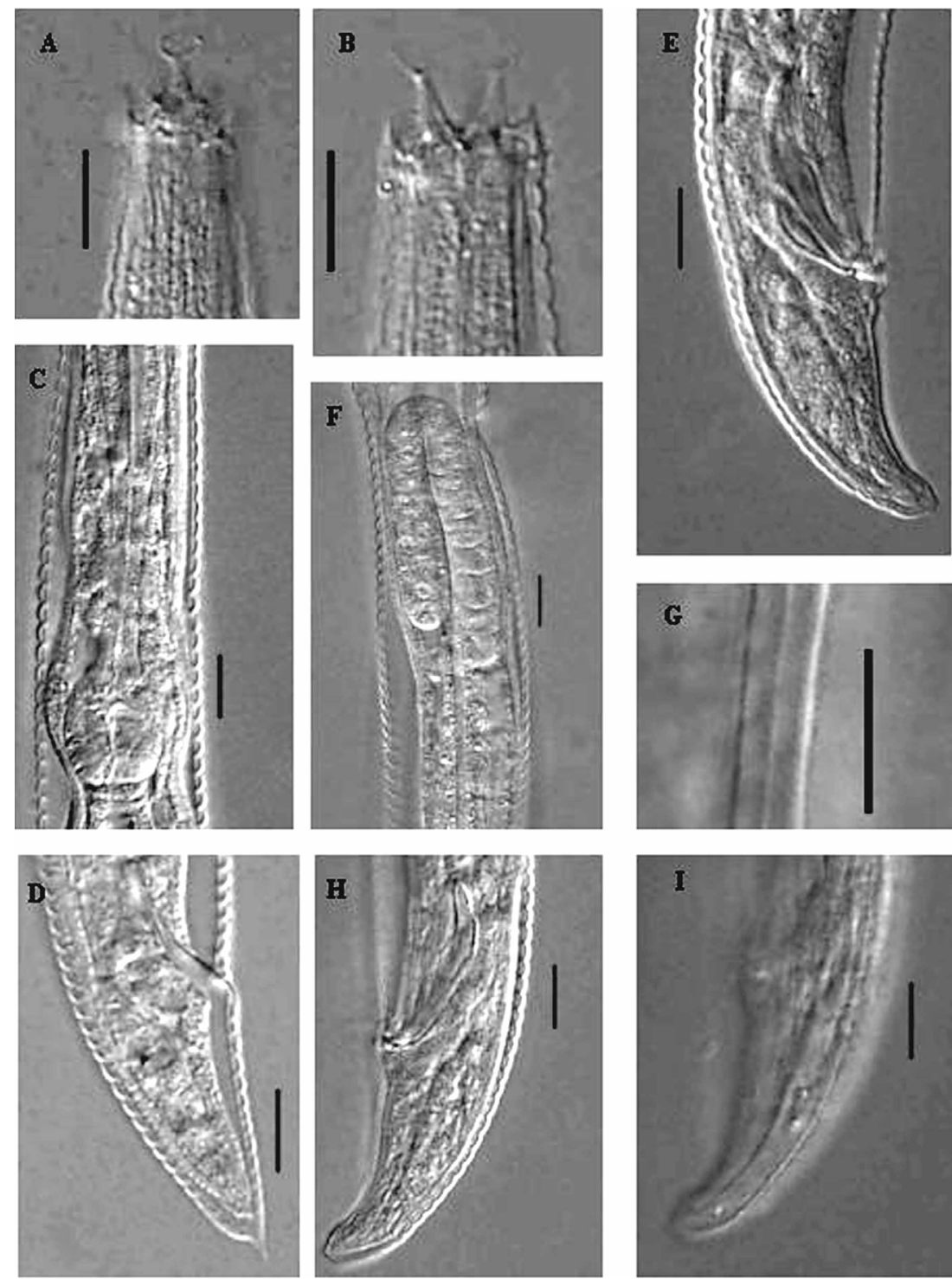

Figure 1. Cervidellus vexilliger A \& B - Anterior regions; C - Pharynx; D - Female tail; $E$ - Male posterior region; F - Male gonad; G - Lateral lines; $H$ - Male spicule; I - Male genital papillae. $($ Scale $=10 \mu \mathrm{m})$ 
Table 1. Measurements of Cervidellus vexilliger, Chiloplacus demani and Acrobeloides nanus (All measurements are in $\mu \mathrm{m}$ )

\begin{tabular}{|c|c|c|c|c|}
\hline Character & \multicolumn{2}{|c|}{ Cervidellus vexilliger } & \multirow{2}{*}{$\begin{array}{c}\text { Chiloplacus demani } \\
\text { Females }\end{array}$} & \multirow{2}{*}{$\begin{array}{c}\begin{array}{c}\text { Acrobeloides nanus } \\
\text { Females }\end{array} \\
38\end{array}$} \\
\hline $\mathrm{n}$ & 15 & 4 & & \\
\hline Body length & $411-455$ & $420-525$ & $614-727$ & $342-501$ \\
\hline a & $19.8-22.8$ & $19.0-23.8$ & $24.5-30.2$ & $19.0-25.0$ \\
\hline $\mathrm{b}$ & $3.7-4.1$ & $4.1-4.4$ & $2.3-4.7$ & $2.7-3.9$ \\
\hline c & $13.7-16.2$ & $16.3-17.5$ & $12.3-18.2$ & $13.6-21.2$ \\
\hline$c^{\prime}$ & $1.6-2.0$ & $1.3-1.8$ & $2.3-2.9$ & $1.6-2.0$ \\
\hline V & $66-68$ & - & $59-68$ & $54-62$ \\
\hline Labial probolae & $3-5$ & $3-5$ & $5-6$ & $5-6$ \\
\hline Stoma & $5-6$ & $5-6$ & $12-14$ & $12-14$ \\
\hline Pharynx length & $109-116$ & $100-120$ & $152-290$ & $115-128$ \\
\hline Excretory pore-ant. end & $55-65$ & $48-62$ & $80-125$ & $70-80$ \\
\hline Maximum body width & $18-22$ & $22-23$ & $24-25$ & $18-25$ \\
\hline Postuterine sac & $20-30$ & - & $16-27$ & $8-12$ \\
\hline Rectum & $15-17$ & $5-6$ & $25-30$ & $13-15$ \\
\hline Anal body width & $15-16$ & $16-19$ & $16-17$ & $12-15$ \\
\hline Tail length & $27-30$ & $25-30$ & $38-50$ & $20-32$ \\
\hline Vulva - ant. end & $28-305$ & - & $365-465$ & $230-310$ \\
\hline Spicule & - & $22-25$ & - & - \\
\hline Gubernaculum & - & $14-15$ & - & - \\
\hline
\end{tabular}

15-17 $\mu \mathrm{m}$ long. Reproductive system, monodelphic, prodelphic. Postuterine sac prominent. Tail conical with a acute terminus. Phasmids at $40-60 \%$ of tail length.

Male: Body usually ventrally curved upon fixation. Reproductive system monorchic. Testis reflexed ventrally. Spicules arcuate with rounded manubrium, calamus as wide as manubrium, lamina ventrally curved and terminus acute. Gubernaculum anteriorly ventrally curved. Five pairs of postanal genital papillae: one pair lateral, one pair subdorsal, one pair subventral and two pairs near tail tip. Tail conical, bearing an acute terminus.

Habitat \& Locality: Soil around the root rhizophere of Myricaria around Pangong Tso and around Caragana bushes around Tsomoriri Lake, Ladakh.

Known Distribution: European regions like Austria, Belgium, Estonia, Germany, Hungary, Italian mainland, Lithuania, Poland, Romania, Sicily, Slovenia, Spanish mainland, Sweden, Ukraine and Netherlands.

Remarks: All the body measurements and description are in conformity with the revised description of the species given by Abolafia et al. (2003) However, slight variation in measurements were observed in body length of males and females (male body length $0.42-0.52 \mathrm{~mm}$ against $0.24-0.4 \mathrm{~mm}$; female body length $0.41-0.45 \mathrm{~mm}$ against $0.22-0.41 \mathrm{~mm}$ ), pharynx length (101-120 $\mu \mathrm{m}$ against 80-107 $\mu \mathrm{m}$ in males; $109-116$ against $72-110 \mu \mathrm{m}$ in females) and values of $c$ is also greater $(c=16.2-17.5$ against $10-14.5$ in males; $13.7-16.1$ against $8.8-15.7$ in females). This species is being found for the first time from Cold Desert, Ladakh and it is a new record from India.

\section{Acrobeloides nanus (de Man, 1880) Anderson, 1968 (Fig. 2 A-E)}

1880. Acrobeloides nanus de Man, Tijds. Nederland.Dierk. Vereen.5: 1-104.

1968. Acrobeloides nanus Anderson, Can. J. Zool., 46: 309-320.

Material Examined: 24.vii.2008, 11 females, Pangong Tso, Ladakh, J \& K, India, coll. A.N. Rizvi, NRS/ZSI/ IV/N/403; 26.vii.2008, 20 females, Tsomoriri Lake, Ladakh, J \& K, India, coll. A.N. Rizvi, NRS/ZSI/IV/N/404; 21.vii.2008, 7 females, Tsokar Lake, Ladakh, J \& K, India, coll. A.N. Rizvi, NRS/ZSI/IV/N/405.

Measurements: Refer Table1.

Description: Female: Body small. Straight to slightly curved upon fixation. Cuticle annulated. Lateral field marked by five incisures. Lip region slightly expanded, with three labial probolae. Labial probolae showing variable morphology mainly high with conical and swollen basal part and thin and acute distal end. Lips conoid with or without minute cephalic probolae. Stoma cephaloboid. Pharyngeal corpus forming an elongated spindle shaped swelling, isthmus leading to a well-developed valvate basal bulb. Reproductive system monodelphic prodelphic. Ovary straight or with double flexure beyond 

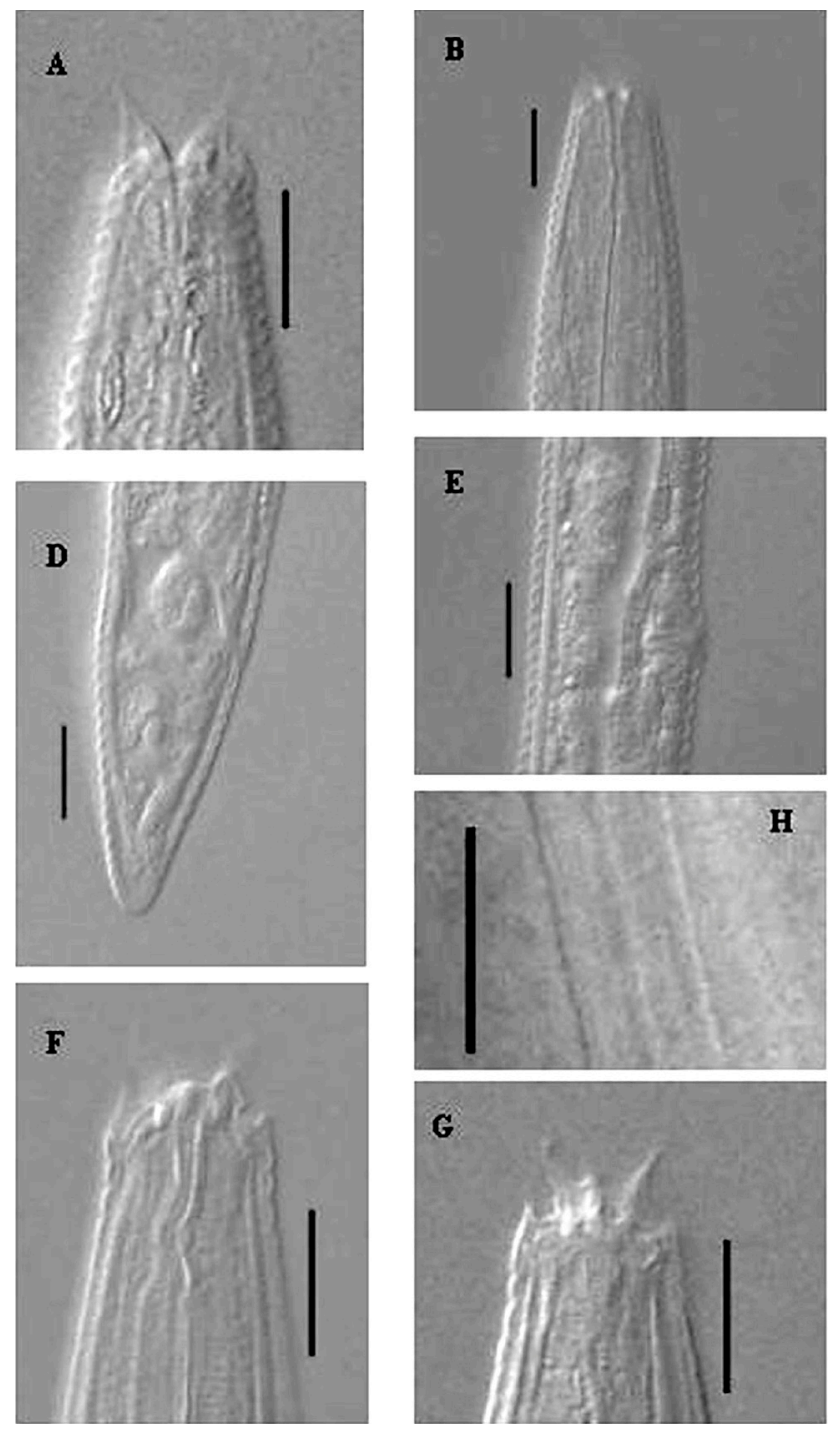

vulva. Postuterine sac very small. Tail variable in shape from conical to rounded terminus to bearing a minute spine.

Male: not found.

Habitat and Locality: Soil around the root zone of Myricaria around Pangong Tso and Caragana bushes around Tsomoriri and Tsokar lakes, Ladakh.

Known Distribution: In India: Uttarakhand; Elsewhere: European regions like Balearic island, Belgium, Czech Republic, Germany, Estonia, Hungary, Italian mainland, Lithuania, Poland, Romania.

Remarks: All the body measurements and description are in agreement with the revised description of the species given by Abolafia \& Santiago (2003a). However, slight variations in measurements were observed in pharyngeal length (115-128 $\mu \mathrm{m}$ against 94-125 $\mu \mathrm{m})$ tail length (20-32 $\mu \mathrm{m}$ against $16-29 \mu \mathrm{m})$. This species is being recorded for the first time from Cold Desert, Ladakh and forms new distributional record from the state of Jammu \& Kashmir. It was recorded for the first time from India by Rizvi (2010)
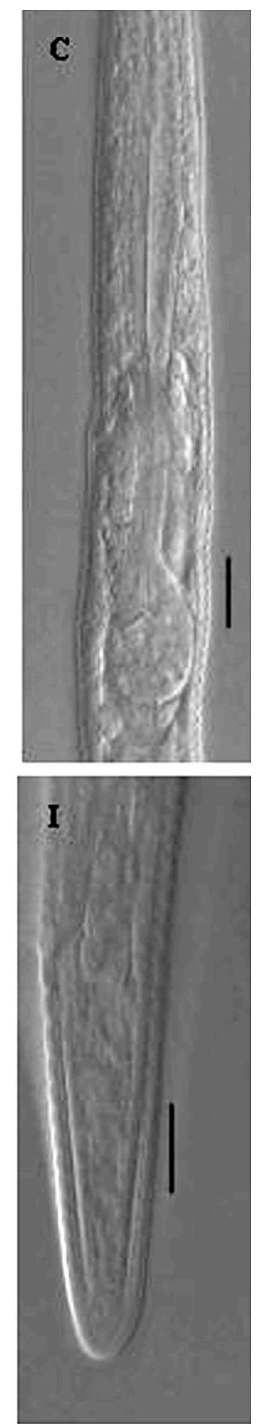

Figure 2. Acrobeloides nanus (A-E), Chiloplacus demani (F-I).

A - Lip region; B - Buccal cavity;

C - Pharynx; D - Tail; E - Vulval region;

F - Buccal cavity; G - Lip region;

H - Lateral lines; I - Tail. (Scale $=10 \mu \mathrm{m})$

from Uttarakhand.

\section{Chiloplacus demani (Thorne, 1925) Thorne, 1937 (Fig. 2 F-I)}

1925. Acrobeles demani Thorne, Trans. American Mics. Soc., 44: 171-210

1937. Chiloplacus demani Thorne, Proc. Helminth. Soc. Wash., 4:1-16

Material Examined: 24.vii.2008, 10 females, Pangong Tso, Ladakh, J \& K, India, coll. A.N. Rizvi, NRS/ZSI/ IV/N/406; 26.vii.2008, 8 females, Tsomoriri Lake, Ladakh, J \& K, India, coll. A.N. Rizvi, NRS/ZSI/IV/N/407; 21.vii.2008, 2 females, Tsokar Lake, Ladakh, J \& K, India, coll. A.N. Rizvi, NRS/ZSI/IV/N/408

Measurements: Refer Table1.

Description: Female: Body ventrally curved upon fixation. Cuticle distinctly annulated. Lateral field marked by three incisures. Lip region with six lips amalgamated in pairs. Primary axils deep, U-shaped and secondary axils shallow, V-shaped. Labial probolae 5-6 um high. 
Stoma cephaloboid. Pharyngeal corpus slightly fusiform, corpus isthmus junction not distinct. Basal bulb ovoid and valvate. Reproductive system monodelphic prodelphic. Postuterine sac 16-27 $\mu \mathrm{m}$ long. Tail conoid with a truncated terminus, subcylindrical. Phasmids at $45-50 \%$ of tail length.

Male: not found.

Habitat \& Locality: Soil from the root zone of Myricaria around Pangong Tso and around Caragana bushes near Tsomoriri and Tsokar lakes, Ladakh.

Known Distribution: European regions like Belgium, Hungary, Poland, Slovenia, Spanish mainland, Netherlands, several localities in Iberian Peninsula.

Remarks: All the body measurements and description are in conformity with the revised description of the species given by Abolafia \& Santiago (2003b). However, slight variation in measurements were observed in body width (24-26 $\mu \mathrm{m}$ against 27-35 $\mu \mathrm{m})$ pharynx length (152$290 \mu \mathrm{m}$ against $156-218 \mu \mathrm{m})$ and values of $\mathrm{a} \& \mathrm{~b}(\mathrm{a}=$ $24.5-30.2$ against 19.1-25.8; $b=2.3-4.7$ against 3.2-4.5) This species is being found for the first time from cold desert, Ladakh and it is a new record from India.

Discussion: From the foregoing observations and records of the known occurrence of all the three species reported here, in Europe and other Palaearctic countries, their occurrence in the Cold Desert region of $\mathrm{J} \& \mathrm{~K}$ India is not surprising but conforms with the zoogeographical pattern of distribution of the Invertebrate fauna. The
Ladakh region in the trans-Himalayan zone is considered to harbour both Palaearctic and Oriental elements.

\section{REFERENCES}

Abolafia, J., O. Holovachov, S. Bostrom \& R. Pena-Santiago (2003). Nematodes of the order Rhabditida from Andalucia Oriental, Spain. The genus Cervidellus Thorne, 1937, (Cepahlobidae) with additional data on of $C$. hamatus Thorne, 1937. Nematology 5(5): 753-776.

Abolafia, J. \& R. Pena-Santiago (2003a). Nematodes of the order Rhabditida from Andalucia Oriental, Spain. The genus Acrobeloides (Cobb, 1924) Thorne, 1937 with description of $A$. arenicola sp. nov. and a key to its species. Journal of Nematode Morphology and Systematics 5(2): 107-130.

Abolafia, J. \& R. Pena-Santiago (2003b). Nematodes of the order Rhabditida from Andalucia Oriental, Spain. The genus Chiloplacus Thorne, 1937, with description of $C$. maginensis sp. n. and a key to species. Nematology 5(2): 243-274.

Mushtaq, P. \& W. Ahmad (2006). Five new and two known species of Dorylaimidae (Nematoda) from Jammu and Kashmir State, India. International Journal of Nematology 16: $19-34$

Rizvi, A.N. (2010). Nematodes associated with Insect pests and soil of teak and sal forests of Dehradun (Uttarakhand), India. Records of the Zoological Survey of India Occasional Paper 317: 1-141.

Zaki, F.A. \& A.A. Mir (1994). First record of ear cockle disease Anguina tritici (Steinbuch, Filipjev) on wheat in cold arid desert zone of Ladakh. Indian Journal of Nematology 24: 228-229. 